\title{
RESENHA
}

\section{RAMOS, Jânia M. O espaço da oralidade na sala de aula.São Paulo: Martins Fontes, 1997.}

Elcemina Lucia Balvedi Pagliosa Universidade Regional Integrada do Alto Uruguai e das Missóes

\footnotetext{
quem se introduz na leitura desta obra de Jânia M. Ramos, A chama atenção a forma didática e a linguagem clara usadas 1 para dizer do propósito daquilo que estará escrito nas quase cem páginas seguintes.

Obra sintonizada com o que preceituam os Parâmetros Curriculares Nacionais sobre o Ensino da Língua Portuguesa, vai da descrição e uso das diferentes modalidades de língua às mais recentes teorias do estudo do texto, "revisitando" aspectos da gramática tradicional e abordando-os, como bem coloca a autora, sob um novo enfoque, tanto na concepção quanto no tratamento.
} 
O espaço da oralidade na sala de aula, além do prefácio e da introdução, registra mais seis capítulos, seguidos de conclusão, notas e referências bibliográficas, sempre calcados no fato de que o "propósito do presente volume é mostrar que um espaço maior deverá ser dedicado ao uso da linguagem oral. Desse modo, esperase afetar positivamente o processo de produção do texto escrito" (p.VIII).

A Introdução predispõe sobremaneira o leitor a conhecer a obra. Deixa claro que apresentará "sugestões de atividades didáticas que contribuam para o aprimoramento da tarefa de produzir textos em língua materna. A clientela visada é a de professores de $1^{\circ}$ e $2^{\circ}$ graus". Concebendo o texto falado como ponto de partida para se chegar à produção do texto escrito, fator importante para o aprendiz, são propostos exercícios a partir das diferenças entre fala e escrita.

Diz, ainda na Introdução, que a proposta é uma forma de contribuir para "minimizar o problema da postura repressiva da escola em relação aos falantes do dialeto não-padrão"; "permitir reflexões sobre língua/linguagem", dada a naturalidade com que será tratada a variação lingüística; "levar à construção de conhecimentos por parte do aluno"; "chamar a atenção para as razões de natureza social... responsáveis pela atitude preconceituosa contra aqueles que falam diferente do padrão culto" (p.XI ).

No Capítulo 1, referindo-se à descrição e uso da língua, norma culta e modalidade oral e escrita, há preciosas afirmações, e que se constituem, a meu ver, em graves denúncias sobre o que se ensina e o que se cobra do aluno: "...é freqüente o professor de língua materna gastar a maior parte de seu tempo ensinando análise sintática, regras de acentuação e pontuação e na hora da avaliação exigir que o aluno escreva um texto" (p. 2). E mais: "Quem quiser avaliar produção de texto deverá treinar produção de texto" (p.2). Estas considerações evidenciam, sem dúvida, o descompasso entre as pesquisas lingüísticas e a prática escolar. E vale lembrar que não são os organismos oficiais que estão a provocar este estado de coisas. "O programa oficial já sugeriu que se enfatizasse, no primeiro grau, o uso da língua e não a descrição" (p.3). 
Há que se ressaltar ainda, neste capítulo, a clareza acerca de norma culta e norma padrão e gramática normativa e gramática descritiva, o que conduz a estudos sobre estilo, e donde decorrem apreciáveis relações sobre as modalidades oral e escrita.

No Capítulo 2, ao tratar da Produção de textos, deixa claro que são objeto de sua preocupação tanto o texto oral quanto o texto escrito. Mas o que chama verdadeiramente a atenção do leitor, especialmente aquele iniciado na Lingüistica Textual, é o "faz de conta" no ato de produzir um texto em sala de aula: o aluno adota uma estrutura frasal que não lhe é usual; um vocabulário que ele considera "bonito" aos olhos do professor; uma argumentação mais pautada em "chavões" do que em indicadores de coesão e coerência, e por aí afora. Tudo isso resultado de uma falsa concepção do que seja a norma culta e do real papel do aluno e do professor nesta tarefa de construir um texto. "Atualmente, o papel do professor tem sido, ao mesmo tempo, de revisor e de destinatário do texto do aluno. Esse estatuto duplo e ambíguo traz conseqüências negativas: é destinatário porque é para ele que o aluno envia seu texto, embora não seja o destinatário pretendido pelo aluno. Nenhum aluno, salvo raras exceções, escreve para o professor, embora todo o aluno lhe entregue seus textos. A conseqüência é que a maioria dos textos, senão todos, são textos escritos para destinatário real nenhum, mas sim para um simples arremedo do destinatário. Não é de se estranhar que a maioria dos "textos" não tenha sentido" (p.16-17). E, o professor, como revisor do texto, é mais uma vez um arremedo, pois não havendo um destinatário real (“...sem alguém para quem o texto deveria ser claro e relevante") as anotações feitas por ele não motivam o aluno a levá-las a sério e refazer a produção.

Os conteúdos expressos nos Capítulos 3, 4 e 5 são de uma clareza metodológica vista em poucas obras do gênero. Começa por oferecer sugestões de como coletar e trabalhar a norma culta na modalidade oral, encaminhando-a, a seguir, para o processo da produção escrita do texto. A seleção de textos veiculados em diferentes meios de comunicação, a atualidade e adequação à faixa etária trabalhada tornam o estudo altamente estimulante. Exempli- 
ficando: "Assistir à TV é algo que, de modo geral, faz parte do cotidiano do aluno e do professor... Não é difícil citar um programa em que o uso da língua padrão seja típico. ... Selecionar uma notícia que seja do interesse dos alunos, anotá-la ou registrá-la em fita cassete ou vídeo, não é, certamente, uma tarefa difícil ou mesmo desagradável" (p.21).

Propõe "(a) seleção de texto a ser gravado; (b) transcrição do texto pelo professor; (c) audição do texto original; (d) análise crítica do texto; (e) leitura da transcrição, ouvindo a fita; (f) leitura da transcrição, seguindo ou não o padrão de entoação ou pronúncia da fita; (g) redação do texto da notícia ou relatório da atividade realizada na sala naquela aula” (p.21). Esta é apenas uma das muitas sugestões. Nada há de parecido com o que comumente se vê sendo feito: o professor repetindo as mesmas aulas que teve quando era aluno há duas, três ou mais décadas.

O capítulo IV, Do uso da norma culta na modalidade escrita, indica atividades de leitura e escrita, tendo como ponto de partida peças de teatro, notícias de jornal e instruções de uso contidas em manuais, bulas de remédio, etc. O que é exemplar neste capítulo é a possibilidade de se trabalhar essa metodologia em diferentes graus e séries do ensino formal, bem como a quebra de monotonia resultante de aulas desse tipo.

"Sugerir um conjunto de normas para transcrição e atividade de "tradução" de textos falados em textos escritos" é a essência do Capítulo 5. Embora a base teórica apresentada, especialmente no que formula Marcuschi, seja de irrefutável valor, o professor-leitor, mesmo saído dos Cursos de Letras recentemente, apresentará alguma dificuldade de domínio da terminologia utilizada, mesmo que os exemplos sejam altamente elucidativos. Observa-se: "... introdução da paragrafação sem modificações da ordem dos tópicos discursivos"; "introdução de marcas metalingüísticas para referenciação de ações e verbalização de contextos expressos por dêiticos", e daí por diante. Este deverá ser o capítulo em que o leitor necessitará ser mais atento, e, quem sabe, já remeter-se a outras leituras elencadas nas referências bibliográficas. Capítulo cujo conteúdo é pouco trabalhado em sala 
de aula (pesquisas vêm demonstrando isso), tanto em escolas de $1^{\circ}$. e $2^{\circ}$. graus, quanto nos cursos superiores que habilitam professores.

O Capítulo 6 poderá surpreender aqueles que são sempre afeitos às últimas "modernidades" do ensino de línguas, e que ficam a proclamar que os princípios da gramática normativa estão em total desuso. A autora deixa claro, mais uma vez, que após a produção de um texto, erros, tais como os de concordância, pontuação, acentuação, ortografia, coesão, coerência, regência e vocabulário, devem ser revistos, mas sob uma nova ótica e outra metodologia.

A autora confirma, neste capítulo, o que escreve nas páginas 6 e 7: "Quem negaria que as gramáticas normativas são instrumentos úteis para dirimir dúvidas quanto à regência de um verbo, ao uso de hífen ou a um determinado tipo de concordância? Veja-se que fazer uso de uma gramática como obra de referência é algo muito diferente de fazer uso desse material como modelo de descrição lingüística".

Assim, entende-se que tais erros, à luz do que preceitua a gramática tradicional, deverão ser avaliados por professor e aluno, numa tarefa conjunta e sistemática. Isso se aplica, especialmente, ao item pontuação, uma vez que a intencionalidade do autor ao escrever é essencial para o entendimento do texto, advindo daí questões outras, como as de coerência, e por que não, também de coesão.

$\mathrm{Na}$ Conclusão, uma matriz de avaliação dos textos escolares é apresentada, como forma de sintetizar todo o trabalho desenvolvido na obra.

Notas, ao final de obra, são sempre bem-vindas, especialmente por oferecerem ao leitor subsídios importantes para uma leitura mais eficaz. Das referências bibliográficas constam autores de reconhecida contribuição para a lingüística. No entanto, o que chama a atenção, positivamente, são referências a textos provenientes de simpósios e seminários, ainda não disponíveis no mercado.

O livro O espaço da oralidade na sala de aula torna-se, por isso tudo, um notável auxiliar do professor, não só em $1^{\circ}$ e $2^{\circ}$ graus, como dimensionou a autora, mas também em $3^{\circ}$ grau. Resta, no entanto, ter clareza de que o professor que se aventurar a aplicar, em sala de aula, a metodologia que vai do oral ao escrito, na feitura do texto, 
não poderá fazê-lo sem antes tornar-se um estudioso da língua, um leitor eficiente, e um organizador progressivo e constante de suas aulas.

Fica claro, ainda, que ensinar a produzir texto não se faz de forma assistemática, e muito menos sem estudo das contribuições e da validade de diferentes correntes lingüísticas, que vão da gramática tradicional aos recentes estudos da lingüística textual.

Se no início desta resenha afirmei que os conteúdos tratados nesta obra estão em consonância com os Parâmetros Curriculares Nacionais, e daí seu inegável valor, não me recuso o direito de afirmar que os Parâmetros, por si só, sem a intervenção das Universidades, não mudarão o rumo do que se ensina nas escolas. E esta obra de Ramos torna-se um excelente referencial a todos quantos estiverem envolvidos na tarefa de fazer acontecer o ensino da língua materna. 